\title{
Minority carrier bulk lifetimes through a large multicrystalline silicon ingot and related solar cell properties
}

\author{
S. Martinuzzi ${ }^{1, a}$, M. Gauthier ${ }^{2}$, D. Barakel ${ }^{1}$, I. Périchaud ${ }^{1}$, N. Le Quang ${ }^{2}$, O. Palais ${ }^{1}$, and G. Goaer ${ }^{2}$ \\ 1 Université Paul Cézanne Aix-Marseille III- Faculté des Sciences et Techniques 13397 Marseille Cedex 20, France \\ 2 Photowatt Int. SA, ZI Champfleuri, 38300, Bourgoin Jailleu, France
}

Received: 13 March 2007 / Accepted: 9 July 2007

Published online: 31 August 2007 - C) EDP Sciences

\begin{abstract}
The bulk lifetime $\tau_{n}$ and diffusion length $L_{n}$ of minority carriers vary through the height of a cast multicrystalline silicon (mc-Si) block. This variation is due to the segregation of metallic impurities during the directional solidification and the native impurity concentrations increase from the bottom to the top of the ingot, which is solidified last, while the ingot bottom, which is solidified first, is contaminated by the contact with the crucible floor. It is of interest to verify if a correlation exists between the bulk lifetime $\tau$ of as cut wafers and the conversion efficiency $\eta$ of solar cells. In a very large ingot $(>310 \mathrm{~kg})$, it was found that $\tau_{0}$, in raw wafers, $\tau_{d i f}$ in phosphorus diffused ones and $L_{n}$ in diffused wafers are smaller in the top and in the bottom of the ingot. The same evolution is observed in solar cells, however the diffusion length values $L_{c e l}$ in the central part of the ingot are markedly higher than those found in diffused wafers, due to the in-diffusion of hydrogen from the SiN-H antireflection coating layer. The variations of $\eta$ and those of $\tau_{0}$, along the ingot height, are well correlated, suggesting that the evaluation of $\tau_{0}$ can predict the properties of the devices. In addition, segregation phenomena around the grain boundaries are observed at the bottom of the ingots, due to a marked contamination by the crucible floor, and at its top where impurities are accumulated. These phenomena are linked to the long duration of the solidification process and the large amount of imperfect silicon used to cast the ingot.
\end{abstract}

PACS. 68.35.Dv Composition, segregation; defects and impurities - 72.20.Jv Charge carriers: generation, recombination, lifetime, and trapping

\section{Introduction}

In cast multicrystalline silicon (mc-Si) the interaction between extended defects and impurities control the values of the lifetime $(\tau)$ and diffusion length $(L)$ of minority carriers. Extended defects are essentially grain boundaries (GBs) and dislocations whose density and distribution are related to ingot growth conditions, especially to its high solidification rate. Impurities come from the feedstock (mostly waste from the microelectronic industry), from the walls of the crucible in which the ingot is cast and also from the atmosphere within the furnace. Metallic contaminants are $\mathrm{Fe}, \mathrm{Cr}, \mathrm{Ni}, \mathrm{Cu}, \mathrm{Al}$ and Ti. During the directional solidification of the ingot the melted silicon charge is solidified progressively from the bottom of the ingot - i.e. the part which is in contact with the crucible floor and which solidifies first-to the top which solidifies last. The metallic atoms, whose solubility is higher in the liquid than in the solid phase, are transported to the top of the ingot by a segregation phenomenon (in accordance

\footnotetext{
${ }^{a}$ e-mail: santo.martinuzzi@univ.u-3mrs.fr
}

with the Scheil law), because their solid-liquid segregation coefficients are extremely small.

This was well observed [1-4] in the central part of cast ingots where the concentration of impurities incorporated into the solid phase $C_{S}$ during the crystallisation is given by:

$$
C_{S}=k_{e f f} C_{L}
$$

with $C_{L}$ the impurity concentration in the liquid phase far from the interface, and $k_{\text {eff }}$ an effective segregation coefficient which depends on the growth rate, on the diffusivity of the impurities in the liquid and on the thickness of the solid/liquid boundary layer at the interface [1].

The very top of the ingot is so concentrated in impurities that it cannot be used to make solar cells and must be discarded. The back solid state diffusion of fast diffusers from the very top of the ingot leads to a contamination of the lower top of the ingot during cooling.

During the growth of the ingot, its very bottom is continuously in contact with the floor of the crucible and is therefore contaminated through solid state diffusion of impurities contained in the floor and walls of the crucible. Since metal atoms diffuse slowly in solid silicon, this 
contamination of the very bottom of the ingot is less marked than that of the very top. However, in this region of the ingot which solidifies first, the grain size is the smallest and the densities of GBs and dislocations are the highest, due to strain and thermal stress at the beginning of the solidification. This part of the ingot must also be discarded.

These contamination phenomena are more marked when the ingot size and the solidification time increase and additional segregation phenomena can occur at extended defects in the bottom and top of the ingot, developed in the solid phase essentially during the cooling down of the ingot.

In addition to fast diffusers accumulation, it is expected that the concentrations in slow diffusers, like $\mathrm{Al}$ and $\mathrm{Ti}$, also increase from the bottom to the top of the ingot because in the liquid phase the impurity concentration continuously increases during the crystal growth. Lifetime engineering could be used to reveal the nature of metallic impurities, distinguishing between fast and slow diffusers, by means of gettering treatments and dissociation of FeB and $\mathrm{CrB}$ pairs.

It is of interest to verify if a correlation exists between the bulk lifetime measured in as cut or in phosphorus diffused wafers, and the properties of solar cells made by conventional technologies with wafers cut from all the regions of the same ingot, except the very top and the very bottom. Such a correlation opens the way to an in-line selection of the wafers and to a prediction of the cell conversion efficiency before wafers experience the processing steps.

\section{Experimental}

A block was cut from the central part of a large mc-Si ingot so that the influence of the crucible walls could be neglegted. The boron doped ingot characteristics are: weight: $310 \mathrm{~kg}$; height: $28 \mathrm{~cm}$; solidification duration: $\sim 40 \mathrm{~h}$; p-type, and resistivity $\sim 1 \Omega \mathrm{cm}$. Wafers were cut from the bottom ("B"), the middle-bottom ("MB"), the middle ("M"), the middle-top ("MT") and the top ("T") regions of the same ingot, after the very top and bottom had been removed (a few $\mathrm{cm}$ ). The wafers were chemically polished by immersion in a $\mathrm{HNO}_{3}-\mathrm{HF}-\mathrm{CHCOOH}$ solution in order to remove the sawing damages. Three wafers were chosen in each region and were investigated as cut, after phosphorus diffusion at $850{ }^{\circ} \mathrm{C}$ for $30 \mathrm{~min}$ (similar to the standard diffusion process used to make solar cells) or after an intentional gettering treatment due to a long phosphorus diffusion at $900{ }^{\circ} \mathrm{C}$ for $2 \mathrm{~h}$.

Mean values of electron bulk lifetime $(\tau)$ were determined in as cut $\left(\tau_{0}\right)$, phosphorus diffused $\left(\tau_{\text {dif }}\right)$ and gettered $\left(\tau_{g e t}\right)$ wafers, by means of the quasi steady state photoconductance technique [5] at low injection level $\left(\sim 10^{14} \mathrm{~cm}^{-3}\right)$, in order that $\tau$ does not vary significantly with the injection level, whatever is the doping level of the wafers. Lifetime is also measured by the contact less microwave phase shift ( $\mu$ WPS) technique [6]. These measurements could be applied to the wafers before and after any type of treatment, including dissociation of FeB and $\mathrm{CrB}$ pairs, by annealing at $200{ }^{\circ} \mathrm{C}$ or by strong illumination.

Mean values of minority carrier diffusion length $(L)$ were computed from the spectral variations of the measured photocurrent and of the optical absorption coefficient in the near infra-red. The measurements were carried out at low injection level, in as cut $\left(L_{0}\right)$ as well as in phosphorus diffused $\left(L_{\text {dif }}\right)$ and gettered $\left(L_{\text {get }}\right)$ wafers, to corroborate the lifetime variations, under the same injection level and also because $L$, which includes transport properties of minority carriers, is always well correlated with solar cells properties. The collecting structures for $L_{\text {dif }}$ measurements were metal-insulator-semiconductor diodes (9 $\mathrm{nm}$ thick Al layer, electron gun deposited on $\mathrm{Si}$ ) for the determination of $L_{0}$, and $n^{+} p$ junctions resulting from the phosphorus diffusion at $850{ }^{\circ} \mathrm{C}$ for $30 \mathrm{mn}$. The mean values resulted of 36 measurements in each wafer. Light beam induced current (LBIC) scan maps ( $\lambda$ in the range 860 to $940 \mathrm{~nm}$; spatial resolution $\sim 10 \mu \mathrm{m}$ ) were also used to reveal the distribution of recombination centres in the wafers, in the grains as well as at extended defects [7]. Notice that the LBIC scan maps at $940 \mathrm{~nm}$ reveal the same features as those of the diffusion length.

$12.5 \times 12.5 \mathrm{~cm}^{2}$ solar cells were prepared using companion wafers cut from the different regions of the same ingot. Conventional techniques were used: phosphorus diffusion, hydrogen rich silicon nitride (SiN-H) antireflection coating deposition by plasma enhanced chemical deposition at $450^{\circ} \mathrm{C}$ and screen printed metallization. The back surface was covered by an aluminium layer and the entire structure was annealed at $\sim 850{ }^{\circ} \mathrm{C}$ for $20 \mathrm{~s}$ in order to form the ohmic contact, to develop a back surface field effect and to enhance the in-diffusion of hydrogen from the SiN-H layer into the bulk. The cells were characterised by the measurement of minority carrier diffusion length, of photocurrent density $J_{s c}$, photovoltage $V_{o c}$, conversion efficiency $\eta$ and by LBIC scan maps.

\section{Results and discussions}

In as cut wafers, it was found that $\tau_{0}$ and $L_{0}$ are the smallest in the top ("T") and in the bottom ("B") regions, in which $L_{0} \sim 30 \mu \mathrm{m}$ and $\tau_{0}<1 \mu \mathrm{s}$, while $L_{0} \sim 75 \mu \mathrm{m}$ and $\tau_{0} \sim 2.9 \mu \mathrm{s}$ in the middle-bottom ("MB") region. The evolutions of $L$ and $\tau$ along the ingot height are very similar, as shown in Figures 1 and 2, exhibiting a drop at the extremities.

As expected from the Scheil law, metallic impurities accumulate at the very top of the ingot which solidifies last, but this accumulation of impurities is followed by a solid state back-diffusion during the cooling of the ingot, leading to a marked decrease in $L$ and $\tau$.

In "B", $L_{0}$ and $\tau_{0}$ are also lower than in the central part of the ingot. This is due to a solid state diffusion of fast diffusers from the crucible floor.

It would be noticed that, as shown in Figure 2 and indicated in Table 1, $\tau_{o}$ is higher in " $\mathrm{T}$ " than in " $\mathrm{B}$ ", because in "B" the density of extended defects is the highest 


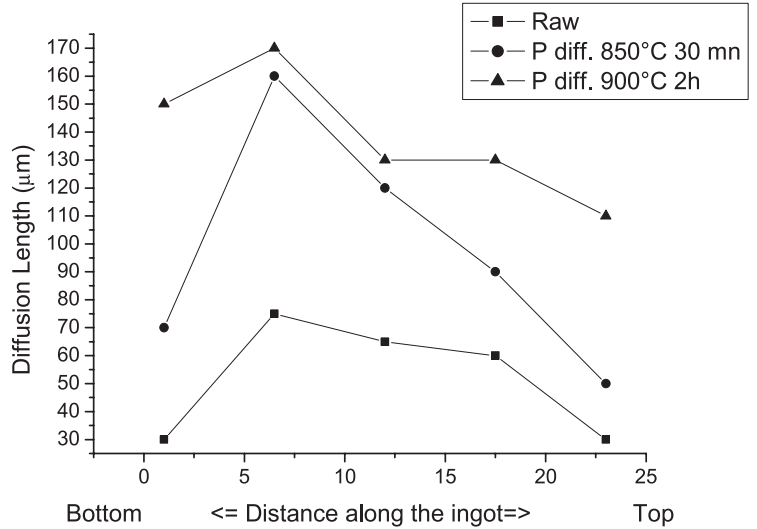

Fig. 1. Variations of minority carrier diffusion length along the ingot height in raw, phosphorus diffused and phosphorus gettered wafers.

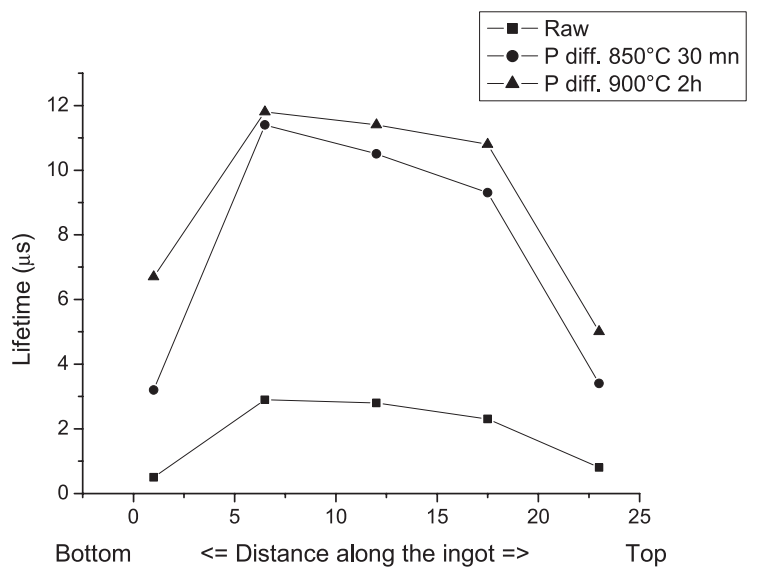

Fig. 2. Variations of bulk minority carrier lifetime along the ingot height in raw, phosphorus diffused and phosphorus gettered wafers.

Table 1. Mean values of minority carrier lifetime before $\left(\tau_{0}\right)$ and after phosphorus diffusion $\left(\tau_{\text {dif }}\right)$ and photovoltaic properties of solar cells.

\begin{tabular}{lccccc}
\hline Ingot regions & "B" & "MB" & "M" & "MT" & "T" \\
\hline$\tau_{0}(\mu \mathrm{s})$ & 0.5 & 2.9 & 2.8 & 2.3 & 0.8 \\
$\tau_{\text {dif }}(\mu \mathrm{s})$ & 3.2 & 11.4 & 10.5 & 9.3 & 3.4 \\
$\tau_{g e t}(\mu \mathrm{s})$ & 6.7 & 13.8 & 13.4 & 12.8 & 5 \\
$J_{s c}\left(\mathrm{~mA} \mathrm{~cm}^{-2}\right)$ & 26 & 33.4 & 33.5 & 33.4 & 27.2 \\
$V_{c o}(\mathrm{mV})$ & 568 & 610 & 608 & 605 & 580 \\
$J_{s c} \times V_{c o}\left(\mathrm{~mW} \mathrm{~cm}^{-2}\right)$ & 14.7 & 20.37 & 20.36 & 20.20 & 15.8 \\
$\eta(\%)$ & 10.3 & 14.9 & 14.5 & 14.3 & 11.2 \\
\hline
\end{tabular}

and impurities, like Fe or Cr which precipitate heterogeneously can be easily trapped, even if their concentrations are well below the solubility limit.

After phosphorus diffusion at $850{ }^{\circ} \mathrm{C}$ for $20 \mathrm{~min}$, these values increase substantially, due to a slight gettering effect which removes impurities which can be easily extracted from the bulk [8]. Figures 1 and 2 show the variations of the mean values of $L_{d i f}$ and $\tau_{d i f}$ as a function of the position along the ingot height and also those of $L_{g e t}$

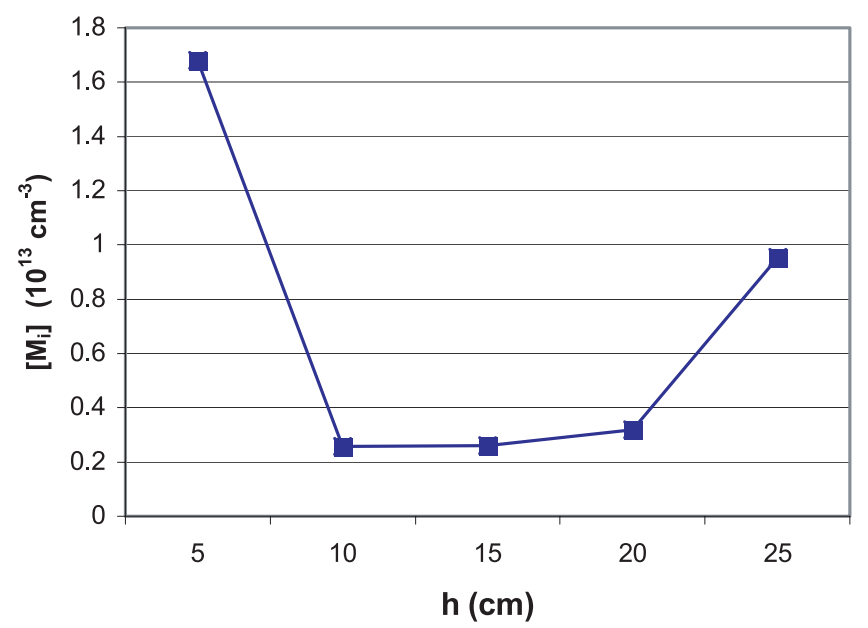

Fig. 3. Computed concentration of fast interstitial diffusers $(\mathrm{Fe} ; \mathrm{Cr} ; \mathrm{Ni} ; \mathrm{Cu})$. Concentrations $\left[\mathrm{Fe}_{i}\right]$ along the ingot height are evaluated through the $\mathrm{FeB}$ pair dissociation.

and $\tau_{\text {get }}$ measured after gettering by phosphorus diffusion at $900{ }^{\circ} \mathrm{C}$ for $2 \mathrm{~h}$.

In "M" and in "MT" the slight decrease in $L_{0}$ and $\tau_{0}$, like that in $L_{d i f}$ and $\tau_{d i f}$, is certainly a consequence of a back diffusion of fast diffusers from the top of the ingot, occurring during the end of the crystallisation and during the cooling down which takes a long time due the large size of the ingot.

Moreover, these decreases of $L$ and $\tau$ in the central part results also of a progressive increase in impurity concentration in the solid, due to an increase in the impurity concentration in the liquid itself, the impurities being partly transferred to the solid.

As expected, the mean values of $L$ and $\tau$ increase after phosphorus diffusion and, obviously, after gettering. However the improvements are more marked in "B" than in "T", suggesting that the impurities are not identical, i.e. in "B" fast diffusers ( $\mathrm{Fe} ; \mathrm{Cr} ; \mathrm{Ni} ; \mathrm{Cu}$ ) are predominant, while in "T" fast and slow (Ti; W; $\mathrm{Al}$ ) diffusers are accumulated by segregation. If the gettering treatment can extract fast diffusers, it is practically ineffective towards slow diffusers, which remain in the wafers and limit $\tau_{\text {get }}$.

From the values of $\tau_{0}$ and of $\tau_{d i f}$, it is possible to deduce a lifetime $\tau_{\mathrm{M} i}$, related to the interstitial metallic atoms $\left(\mathrm{M}_{i}\right)$ which are extracted by gettering during the phosphorus diffusion, according to the expression:

$$
1 / \tau_{\mathrm{M} i}=1 / \tau_{o}-1 / \tau_{\text {dif }} .
$$

Assuming that the capture cross section of the recombination centres related to these interstitial metal atoms is $\sim 10^{-15} \mathrm{~cm}^{2}$, it is possible to evaluate their concentration $\left[\mathrm{M}_{i}\right]$. As shown in Figure $3,\left[\mathrm{M}_{i}\right] \sim 1.7 \times 10^{13} \mathrm{~cm}^{-3}$ in "B", $\sim 2.7 \times 10^{12} \mathrm{~cm}^{-3}$ in the central parts of the ingot, and $\sim 10^{13} \mathrm{~cm}^{-3}$ in "T".

$\left[\mathrm{Fe}_{i}\right]$ is evaluated through the dissociation of the FeB pairs. The values of $\left[\mathrm{Fe}_{i}\right]$ are reported in Figure 3. It is found that $\left[\mathrm{Fe}_{i}\right] \sim 3.5 \times 10^{12} \mathrm{~cm}^{-3}$ in "B", $\sim 4 \times 10^{11} \mathrm{~cm}^{-3}$ in the central regions and $\sim 10^{12} \mathrm{~cm}^{-3}$ in "T". As expected, $\left[\mathrm{Fe}_{i}\right]$ values are lower than the total concentrations 


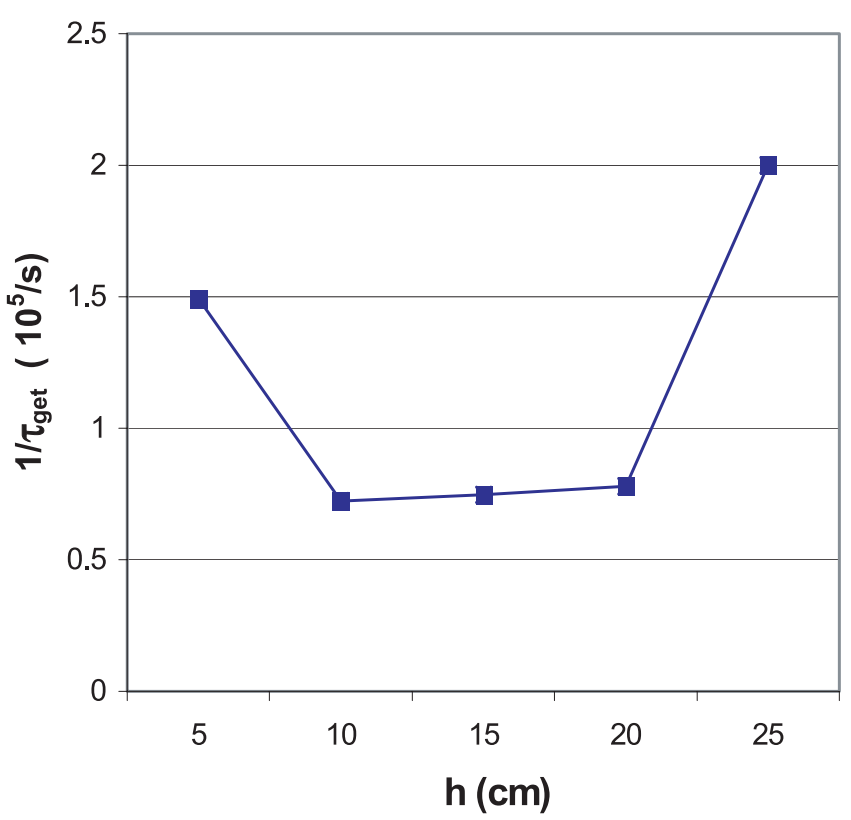

Fig. 4. Variation along the ingot height of recombination centres due slow diffusers, precipitates, complexes and segregated impurities which cannot be removed by gettering.

$\left[\mathrm{M}_{i}\right]$ of interstitial metals, but there are also very low by themselves. This is due to the segregation of metal atoms by extended defects like grain boundaries (GBs) and dislocations, as verified by Mac Donald et al. [1]. These authors used the Fe-B pair dissociation technique and the neutronic activation analysis and showed that the total Fe concentration is certainly two orders of magnitude higher than $\left[\mathrm{Fe}_{i}\right]$.

Notice that the evaluation of $\left[\mathrm{Fe}_{i}\right]$ is minimized by the dissociation of $\mathrm{CrB}$ pairs, which, occurring during the same treatment, tend to increase the lifetime $[9,10]$.

It is also important to determine the variation of the recombination centre concentration due to impurities precipitated or segregated at extended defects and to slow diffusers which cannot be removed by gettering. This variation could be deduced from that of the reverse of $\tau_{\text {get }}$, because it could be reasonably assumed that after phosphorus diffusion at $900{ }^{\circ} \mathrm{C}$ for $2 \mathrm{~h}$ most of fast diffusers are removed whatever is their position in the wafer (interstitial atoms, easily dissolved precipitates in grains and at GBs) $[11,12]$. Figure 4 illustrates this variation and indicates that the concentration of these recombination centres is more marked in " $\mathrm{B}$ " and in "T" than in the central part of the ingot. It is also higher in " $\mathrm{T}$ " than in " $\mathrm{B}$ ", because segregation accumulates impurities at the top of the ingot, among which slow diffusers which cannot be removed by gettering. This is a consequence of the precipitation and segregation at extended defects of impurities coming from the crucible floor and of the accumulation of impurities in "T", linked to the long duration of the solidification process.

$1 / \tau_{\text {get }}$ is higher in " $\mathrm{B}$ " than in the central part, probably because precipitates that are not dissolved by the gettering treatment are formed at the extended defects,

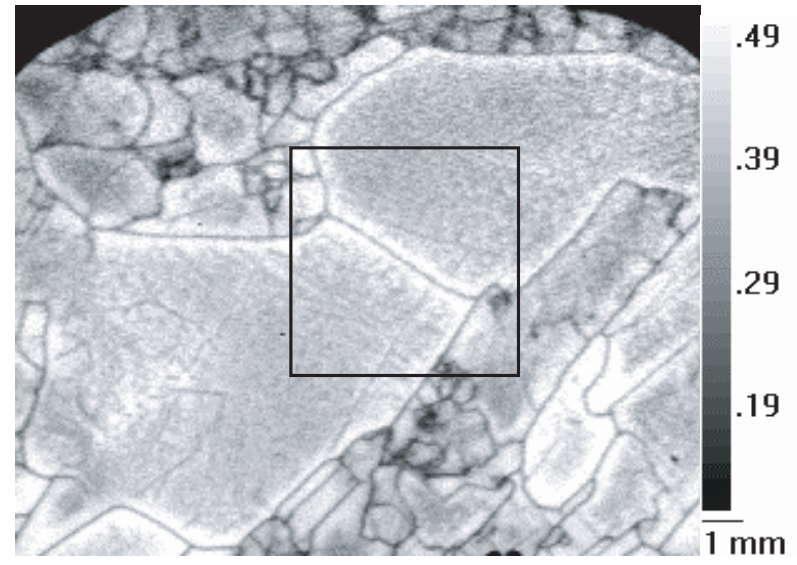

Fig. 5. (Color online) LBIC scan map at $940 \mathrm{~nm}$ of a sample cut out from the top of the ingot.

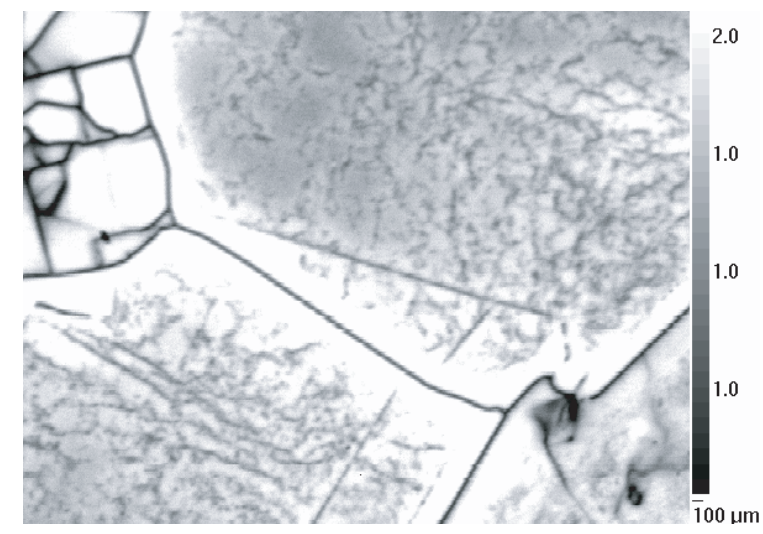

Fig. 6. (Color online) LBIC scan map at $940 \mathrm{~nm}$ of the central region of the sample scanned in Figure 5 and delimited by the frame.

whose density is very high in this region. Such precipitates could be silicates, as proposed in reference [13].

It is admitted that extended defects are certainly sites of enhanced impurity segregation, removing fast diffusers from the homogeneous regions of the grains. Such phenomena are revealed through the LBIC scan maps of samples cut from "B" and "T". As shown in Figures 5 and 6 , the photocurrent $(\lambda=940 \mathrm{~nm})$ is improved around GBs in samples cut from "T". However, the extension of the cleaned regions is small compared to the grain size, and as the recombination activity of extended defects is increased by the trapping of impurities [12], the mean values of $L$ and of $\tau$ in "B" and "T" cannot be improved. In "MB", in "M" and in "MT", the LBIC scan maps do not reveal such segregation effects, because the impurity concentrations are too low.

After gettering, the segregation phenomena observed at GBs in "B" and "T" are always present and the cleaned regions are enlarged, due to the removal of impurities from the wafer bulk. (It is the gettering effect developed by the long phosphorus diffusion which induces the marked increase in $L$ given in Fig. 1.)

The main photovoltaic parameters of solar cells made with companion samples are given in Table 1 . This table 
Table 2. Mean values of minority carrier diffusion length in raw wafers $\left(L_{0}\right)$, in phosphorus diffused ones $\left(L_{\text {dif }}\right)$ and in solar cells $\left(L_{\text {cel }}\right)$.

\begin{tabular}{lccccc}
\hline Ingot region & "B" & "MB" & "M" & "MT" & "T" \\
\hline$L_{0}(\mu \mathrm{m})$ & 30 & 75 & 65 & 60 & 30 \\
$L_{\text {dif }}(\mu \mathrm{m})$ & 70 & 160 & 120 & 90 & 50 \\
$L_{c e l}(\mu \mathrm{m})$ & 70 & 300 & 240 & 280 & 70 \\
\hline
\end{tabular}

shows that a good fit is obtained between the variations along the ingot height of $\eta$ (or of the product $V_{c o} \times J_{s c}$ which is irrespective of the series resistance) and of $\tau_{0}$ and $\tau_{d i f}$. It appears that in "B" and in " $\mathrm{T}$ ", in which $\tau_{0}$ is lower than $1 \mu \mathrm{s}, \eta$ is lower than $11 \%$, while in the central part of the ingot, in which $\tau_{0}$ is higher than $2 \mu \mathrm{s}, \eta$ reaches 14.5 to $15 \%$.

The agreement between the variations of $\eta$ and $\tau_{0}$ is surprising because the material is strongly modified by the processing steps needed to make the cells. It could be emphasized that the initial value $\tau_{0}$ is limited by the presence of a lot of imperfections, i.e. fast diffusers and high extended defects densities in "B", fast and of slow diffusers in "T". The processing steps make it possible to neutralize some of these imperfections, but not all of them, especially slow diffusers and silicates formed at extended defects, which still limit the lifetime and consequently the conversion efficiency of the cells.

As shown in Table 2, the values of electron diffusion length in the cells $\left(L_{c e l}\right)$ are markedly increased in the central part of the ingot compared to those found in phosphorus diffused wafers, except in "B" and in "T". Values higher than $240 \mu \mathrm{m}$ are measured in "MB", "M" and "MT" cells. This is certainly due to the beneficial effect of the in-diffusion of hydrogen from the silicon nitride layer into the wafer, which can passivate extended defects and dissolved impurities $[14,15]$. This passivation is more efficient when the wafers have been previously cleaned by the phosphorus diffusion [16].

The spectral variations of the internal quantum efficiency of the cells suggest that $L_{c e l}$ is not homogeneous: $\sim 100 \mu \mathrm{m}$ layer of material below the front surface is excellent while deeper down the material is less improved, probably because the hydrogen in-diffusion is limited by its trapping at the imperfections [14]. In "T" and "B" the mean value of $L_{c e l}$ are close to those of $L_{d i f}$ because the densities of extended defects and of trapped impurities in "B" are too high (as will be shown by Fig. 8) and because "T" certainly contains slow diffusers accumulated by the segregation, which cannot be passivated by hydrogen.

These segregation phenomena observed at extended defects in the wafers are also observed in solar cells, when they are made with wafers cut from "T" and "B". The LBIC scan map given in Figure 7 (the cell was made with a companion wafer of that scanned in Fig. 5) illustrates. The LBIC scan map of Figure 8 shows that in "B" these segregation phenomena appear also around GBs and that electrically active dislocation networks are revealed in the grains of this region.

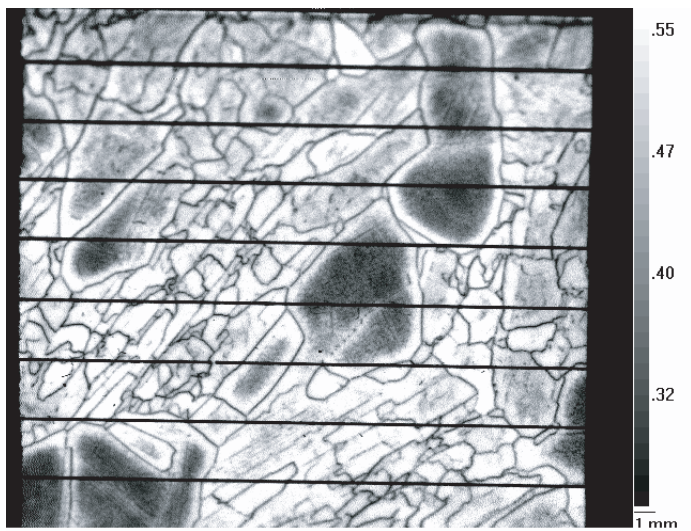

Fig. 7. (Color online) LBIC scan map of a cell made with a wafer cut from the top of the ingot (companion of that of Fig. 5).

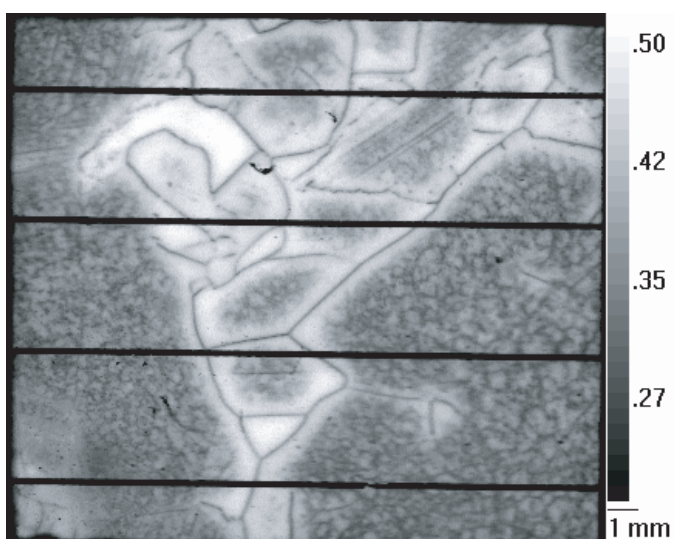

Fig. 8. LBIC scan map at $940 \mathrm{~nm}$ of a region of a cell made with a wafer cut from the bottom of the ingot which shows segregation phenomena around GBs and reveal the presence of electrically active dislocation networks in the grains.

Notice that the segregation phenomena which occur at extended defects in the extremities of the ingot have rarely been observed [17]. They are certainly related to the large quantity of material, and of impurities contained in the material, and also to the long time needed to grow and to cool such a large crystal.

The similarity of the variations of $\tau_{0}$ and $\eta$ along the ingot given in Table 1 suggests that a control of the wafers could, a priori, be very indicative of the future cell conversion efficiency. In line characterisation through measurement of $\tau_{0}$ will suffice to predict the value of $\eta$ and to select or discard wafers. In line characterisations may be done by means of a modified $\mu$ WPS tool which can work with raw or phosphorus diffused wafers, without requiring a surface passivation step for each wafer.

Due to the different impurities contained in "B" (mainly fast diffusers) and in "T" (fast and slow diffusers), the bottom of the ingot could be recycled in another crystallisation process, but not the top, because fast diffusers can be partly removed at least, by phosphorus diffusion

Due to the $28 \mathrm{~cm}$ height of the ingot, crystallisation takes $40 \mathrm{~h}$ and the crystal remains at a sufficiently high 
temperature during a long time, and impurities can diffuse from the crucible into the ingot bottom and back-diffuse from the top in the central part of the ingot. As a recommendation for cost effective crystal growing, the authors suggest to make large crystals in one run but with a height limited to $\sim 15-20 \mathrm{~cm}$, in order to reduce the extension of the bottom and top regions which cannot be used to make acceptable cells.

\section{Conclusions}

The growing of very large mc-Si ingot is cost effective for the industrial production of solar cells, however due to the long time needed to growth and to cool the crystal, solid state segregation phenomena develop at the extremities of the ingots and solid state diffusion must also be taken into account as impurities in-diffuse from the crucible walls and floor into the ingot bottom and back-diffuse from the heavily contaminated top to the central part of the ingot. Only the central part of the ingot is of a high quality.

To reduce the size of the contaminated regions at the extremities of the ingot, the crystallisation time must be decreased, and the ingot height must be limited to about $20 \mathrm{~cm}$.

A consequence of the large size and weight of the ingots is the appearance of impurity segregation phenomena around extended crystallographic defects, in the as cut wafers cut in the extremities of the ingots, as well as cells made with such wafers.

Although the processing steps used to make solar cells improve markedly the material, they do not change the quality distribution of the wafers along the ingot. The best ones (in lifetime higher than $2 \mu \mathrm{s}$ ) are improved during these steps and lead to cell conversion efficiency around $15 \%$, while the wafers cut from the extremities of the ingot (initial lifetime lower than $1 \mu \mathrm{s}$ ) lead to cell conversion efficiency of only $10 \%$.

As-cut wafers could be selected by means of bulk lifetime measurements, before subjecting them the processing steps needed to make the solar cells.
This work was supported by ADEME, French Agency for Environment and Energy Management (France), and by the CNRS - France.

\section{References}

1. D. Macdonald, A. Cuevas, A. Kinomura, Y. Nakano, L.J. Geerligs, J. Appl. Phys. 97, 33523 (2005)

2. L.J. Geerligs, Proc. of 14th Workshop on Crystalline Silicon, NREL, Winter Park-CO. USA, 2004, p. 143

3. A. Bentzen, H. Tathgar, R. Kopecek, R. Sinton, A. Holt, Proc. of the 31st IEEEE Photovoltaics Specialists Conference, Lake Buena Vista Fl, 3-7 January 2005 (IEEE, New York, 2005), pp. 1074-1077

4. K. Peter, R. Kopecek, T. Pernau, E. Enelbakk, K. Friestad, R. Tronstad, C. Dethloff, Proc. of the 31st IEEEE Photovoltaics Specialists Conference, Lake Buena Vista Fl, 3-7 January 2005 (IEEE, New York, 2005), pp. 927-930

5. R.A. Sinton, A. Cuevas, Appl. Phys. Lett. 69, 2510 (1996)

6. O. Palais, J. Gervais, E. Yakimov, S. Martinuzzi, Eur. Phys. J. Appl. Phys. 10, 157 (2000)

7. M. Stemmer, Appl. Surf. Sci. 63, 213 (1993)

8. I. Périchaud, Solar Energy Mat. Solar Cells 72, 315 (2002)

9. S. Dubois, O. Palais, M. Pasquinelli, S. Martinuzzi, C. Jaussaud, J. Appl. Phys. 100, 024510 (2006)

10. A.A. Istratov, H. Hielsmair, E.W. Weber, Appl. Phys. A 69, 13 (1999)

11. J.S. Kang, D.K. Schroder, J. Appl Phys. 65, 2974 (1989)

12. J.C. Muller, S. Martinuzzi, J. Mater. Res. 13, 2721 (1998)

13. S. Mc Hugo, A.C. Thompson, G. Lamble, I. Périchaud, S. Martinuzzi, J. Appl. Phys. 89, 4282 (2001)

14. S. Martinuzzi, I. Périchaud, F. Warchol, Solar Energy Mat. Solar Cells 80, 343 (2003)

15. G. Hahn, D. Sontag, S. Seren, A. Schönecker, A.R. Burgers, R. Ginige, K. Cherkaoui, D. Karg, M. Stavola, Proc. 19th EU Photovoltaic Solar Energy Conf., Paris, France, June 2004 (WIP, Munich, 2004), pp. 427-430

16. I. Périchaud, S. Martinuzzi, J. Phys. III France 2, 313 (1992)

17. M. Rinio, C. Ballif, T. Buonassisi, D. Borchert, in reference [15], p. 507 